\title{
A cross-cultural comparative study of sustainability consciousness between students in Taiwan and Sweden
}

\author{
Teresa Berglund $^{1}$ (D) . Niklas Gericke ${ }^{1}$ Jelle Boeve-de Pauw ${ }^{1,2} \cdot$ Daniel Olsson ${ }^{1}$. \\ Tzu-Chau Chang ${ }^{3}$
}

Received: 20 December 2018 / Accepted: 21 September 2019 / Published online: 10 October 2019

(c) The Author(s) 2019

\begin{abstract}
Education for sustainable development (ESD) is promoted as one important component in the endeavor toward sustainable development. Goal 4 in the Sustainable Development Goals (UN in Sustainable development goals-17 goals to transform our world, 2017) in particular targets the role of ESD in this respect. The importance of cultural specificity in ESD is emphasized in numerous international policy documents, but there are few crosscultural studies that focus on the broad context of sustainable development and ESD. The current study investigates the sustainability consciousness of grade 12 students (age 18-19) in Taiwan $(N=617)$ and Sweden $(N=583)$ and discusses the implications for ESD policy and practice. The findings indicate that significant differences exist between the two samples, both with respect to their sustainability consciousness and within the three subconstructs of knowingness, attitudes and self-reported behaviors. The differences are considered in light of the cultural value orientations of the East Asian and Western European regions. Implications for ESD are discussed from the perspective of cultural specificity.
\end{abstract}

Keywords Sustainable development $\cdot$ Education $\cdot$ Culture $\cdot$ Sustainability consciousness · Knowledge $\cdot$ Attitudes $\cdot$ Behavior

$\begin{array}{ll}\text { Abbreviations } \\ \text { SD } & \text { Sustainable development } \\ \text { ESD } & \text { Education for sustainable development } \\ \text { SC } & \text { Sustainability consciousness } \\ \text { REF } & \text { Reference group of students } \\ \text { SCQ } & \text { Sustainability consciousness questionnaire } \\ \text { RMSEA } & \text { Root mean square error of approximation }\end{array}$

Teresa Berglund

teresa.berglund@kau.se

1 Department of Environmental and Life Sciences, Karlstad University, Universitetsg. 2, 65188 Karlstad, Sweden

2 Research Unit Edubron, Department of Training and Education Sciences, Faculty of Social Sciences, University of Antwerp, S.Gk10.103, 2000 Antwerp, Belgium

3 Graduate Institute of Environmental Education, National Taiwan Normal University, No. 162, Section 1, Heping E Rd, Da'an District, Taipei City 106, Taiwan 
CFI Comparative fit index

TLI Tucker-Lewis index

\section{Introduction}

Creating sustainable development (SD) is one of the biggest challenges that societies around the world face today. The global sustainability debate centers on how to achieve environmental sustainability and at the same time develop our world socially and economically.

At international level, policies have highlighted the important role education plays for SD (e.g., UN-DESA 1992; UNESCO 2006, 2014). These point to the importance of cultural diversity and emphasize that ESD needs to be framed in different ways to adapt to the cultural context (UNESCO 2006, 2014). Culture influences how sustainability issues are viewed and approached in different contexts and situations (Commonwealth Secretariat 2007). Cultural aspects influence the ways environmental, social and economic dimensions and SD are interconnected (UNESCO 2006; Commonwealth Secretariat 2007). According to international policy, ESD should be based on holistic approaches to the environmental, social and economic dimensions of SD and the interconnections between these. Core competencies such as critical and systems thinking and collaborative decision making that empower students to be active in finding solutions to local and global problems are highlighted as important outcomes of ESD (UNESCO 2014). However, policies on SD and ESD are often uniform, despite the emphasis on cultural adaptation. According to the Global Action Programme (GAP), launched by UNESCO in 2014, one goal of ESD is that everyone should have "the opportunity to acquire the knowledge, skills, values and attitudes that empower them to contribute to sustainable development” (p. 34). However, aspects such as values, attitudes and behaviors in the wide and complex context of SD may vary between cultural regions due to different histories and traditions. How this general goal can be achieved in a culture-specific way is a question that requires more research.

More studies are needed in the field of ESD that focus on the cross-cultural perspectives and cultural specificity of ESD (Kopnina and Meijers 2013). Cross-cultural studies with connection to ESD often focus on one of the SD dimensions, such as cross-cultural differences within the environmental dimension. These studies focus on relationships between different psychometric constructs, e.g., values and environmental attitudes (Schultz et al. 2005), or environmental values and behaviors (Aoyagi-Usui et al. 2003; Boeve-de Pauw and Van Petegem 2011a). There is a need for cross-cultural studies focusing on people's understandings, views and actions within the broader context of SD, i.e., including the social and economic dimensions in addition to the environmental dimension.

For some time now, there has been an emphasis on ESD as central to promoting SD globally (e.g., Hopkins 2012; UNESCO 2006, 2014). Respect for cultural diversity is considered an important value in international ESD policy, and ESD is supposed to take different shapes to adapt to the cultural context. In line with studies that have compared different nations in relation to environmentalism (Olsson 2018; Fang et al. 2018; Yu et al. 2019), we aim to investigate and compare the sustainability consciousness (SC) between two groups of senior secondary students that represent two different cultural contexts. These countries belong to distinctly different cultural regions that differ in their value orientations (Schwartz 2004; Hofstede and McCrae 2004; Inglehart and Oyserman 2004). The concept of SC has been applied in different contexts to investigate differences between 
students from ESD-profiled schools and non ESD-profiled schools in Sweden (Berglund et al. 2014; Olsson et al. 2016), differences between students from Green schools and nongreen schools in Taiwan (Olsson et al. 2019), Swedish students' SC in the transition to adolescence (Olsson and Gericke 2016), differences between genders in Sweden (Olsson and Gericke 2017), Swedish students' views of SD in relation to separated and integrated approaches to SD (Berglund and Gericke 2016), the effectiveness of ESD in Sweden (Boeve-de Pauw et al. 2015), and inquiry-based learning among preservice teachers in Pakistan (Kalsoom and Khanam 2017; Kalsoom et al. 2017). The development and validation of the survey instrument measuring SC were reported by Gericke et al. (2019). The present study is the first to use the concept in a cross-cultural investigation.

A survey based on the three sub-constructs of sustainability knowingness, sustainability attitudes and sustainability behaviors was used to investigate the sustainability consciousness (SC) of the students. The construct of SC probes knowingness, attitudes and behaviors in relation to the environmental, social and economic dimensions of SD. Two comparable samples of students were selected that responded to a questionnaire. The data were analyzed using multivariate analysis of variance. By investigating the SC among students in Taiwan and Sweden, we aim to contribute new knowledge to the discussion of cultural differences in the educational context. More specifically, we aim to shed light on cultural differences relevant for education and discuss their implications in the specific context of ESD.

\section{Study framework}

\subsection{Sustainable development, education and culture}

Most definitions of SD are based on the three dimensions of the environment, the society and the economy (e.g., UNESCO 2006; Giddings et al. 2002; Jabareen 2008). Solutions to sustainability problems should therefore be based on considerations of environmental, social and economic perspectives. Finding solutions to sustainability problems is often challenging due to conflicts between different interests (e.g., Jickling and Wals 2008; Herremans and Reid 2002; Öhman and Öhman 2012). At a general level, there is, for example, a discussion about whether the goals of economic growth and environmental sustainability are compatible, a discussion relating to over-consumption, over-exploitation of nature's resources and the impact on the regenerative capacity of ecosystems (e.g., Munda 1997; Ekins 2000; Aşici 2013). A recent study investigated how young adults in Sweden view the relationships between economic growth, economic development and SD and found a number of different ways that young people view these relationships (Berglund and Gericke 2018). In addition, the multidimensionality of SD gives rise to different interpretations among people or groups with respect to what is regarded as sustainable in specific situations (Rauch 2002; Jickling and Wals 2008). Underlying value differences can contribute to different views and priorities (Herremans and Reid 2002; Berglund and Gericke 2016).

The importance of including values in ESD that empower young people to contribute to SD is emphasized both in international policies and in research (e.g., UNESCO 2006, 2014; Herremans and Reid 2002; Öhman 2008; Le Grange 2013). Le Grange (2013) outlines core values central to SD, based on the perspectives of people and nature (ecological sustainability) and people and people (the social justice principle). People- and naturerelated values concern people as part of and dependent upon nature; respect for all forms of 
life (biodiversity and interspecies equity); careful use of biophysical resources and restoration of degraded ecosystems. The people and people perspective includes core values such as basic human needs, inter-generational equity concerning planetary conditions, human rights and freedom of expression, religion, conscience etcetera and the ability to participate and exercise responsibility for one's own life (Le Grange 2013). However, mainstream notions of SD have been criticized for the emphasis on Western values compared to other value systems, for example in relation to the interpretation of SD (Thaman 2002) and in relation to the routes toward SD (Commonwealth Secretariat 2007).

In international policy documents on ESD, the aspect of culture is emphasized as important. However, it comes into play at different levels, and the ways culture and SD/ ESD relate are often vaguely described. In the Framework for the UN Decade of Education for Sustainable Development, culture is described as an underlying aspect of the environmental, social and economic dimensions (UNESCO 2006). As such, culture influences the ways in which aspects of environmental, social and economic dimensions are interconnected. In the definition of SD in the framework, culture is also described as a specific sub-theme to the social dimension of SD, in which respect for cultural diversity and intercultural understanding are central. According to UNESCO (2006, p. 14), culture is "ways of being, relating, behaving, believing and acting" through which people live their lives.

Hofstede and McCrae (2004) describe culture as a collective property, common to some but not all people. According to Schwartz (2004) and Triandis (2004), culture is a complex or a pattern of beliefs, meanings, norms, practices and values shared among people in a society. Cultures differ according to history, traditions and contexts (Triandis 2004; Schwartz 2004; UNESCO 2006) and influence values and practices, attitudes and worldviews (UNESCO 2006; Commonwealth Secretariat 2007; Murray 2011; Boeve-de Pauw and Van Petegem 2011a). Behaviors are an expression of it (Hofstede and McCrae 2004; Schwartz 2004; Kollmuss and Agyeman 2002). There is also a cultural component in the interaction between humans and the environment (Commonwealth Secretariat 2007). Thus, culture influences aspects of human life such as behaviors and values related to the society and the environment. Consequently, cultural aspects are relevant in investigations related to the context of SD and influence the way ESD is or could be shaped in different regions.

\subsection{Cultural value orientations}

Value orientations are often relevant to consider when performing studies across cultures. However, differences between groups are generally small compared to the individual differences within a cultural group (Hofstede and McCrae 2004). Values differ between individuals within a cultural region, but also between different cultural regions (e.g., Schwartz 1992, 2004; Boeve-de Pauw and Van Petegem 2011a; UNESCO 2006). Taiwan and Sweden belong to different cultural regions (Xiaoge 1998; Schwartz 2004; Hofstede and McCrae 2004; Inglehart and Oyserman 2004).

Relationships between value orientations and the regions of East Asia and Western Europe have been identified in research, and some of these are broadly outlined here. The collectivism versus individualism dimension goes under different names but is built on relatively common ground (see, e.g., Maleki and de Jong 2014; Hofstede and McCrae 2004; Schwartz 2004; Inglehart and Oyserman 2004; Triandis 2004). This dimension is characterized as the degree to which individuals are integrated into groups and focuses on the definition of the self as independent or interdependent with some in-group, such as family or co-workers. Societies in East Asia are generally collectivism-oriented, which means that 
the relationship and loyalty to the in-group is important (e.g., Xiaoge 1998; Zhang et al. 2005). The risk of negative evaluation by others in the group is something that people generally try to avoid in a collectivism-oriented society (Triandis 2004). Western European societies are, in general, oriented toward individualism, although different regions display somewhat different features of individualism (e.g., Hofstede and McCrae 2004; Schwartz 2004). Variety, pleasure and autonomy are strongly valued in cultures oriented toward individualism (Hofstede and McCrae 2004). According to Triandis (2004), a horizontal individualist orientation dominates in Sweden, which means that individuals are (group) independent and self-reliant in the Swedish culture, while at the same time, it is important not to stick out too much.

The power distance or hierarchy dimension goes under various names in the literature, but includes many common features (e.g., Maleki and de Jong 2014; Hofstede and McCrae 2004; Schwartz 2004; Inglehart and Oyserman 2004; Triandis 2004). This dimension concerns the extent to which hierarchical relationships and position-related roles are accepted (Hofstede and McCrae 2004). According to Schwartz (2004), who labels the opposing poles of this dimension egalitarianism and hierarchy, both poles aim to maintain social stability and get things done through responsible behavior. Power distance scores are lower for Germanic (to which Sweden belongs) than Asian countries (Hofstede and McCrae 2004). In East Asian culture, values of interpersonal harmony and relational hierarchy are strongly emphasized compared to other cultures (e.g., Xiaoge 1998; Zhang et al. 2005). Solidarity and tolerance with others are facets of the emphasis on interpersonal harmony (Zhang et al. 2005).

The dimension of mastery versus harmony (e.g., Schwartz 2004; Maleki and de Jong 2014) reflects whether people try to control and change the environment in contrast to being in harmony with it. The relationship between humans and nature is one aspect of this dimension, as well as aspects of masculinity and femininity as described by Hofstede (Schwartz 2004; Maleki and de Jong 2014). Acceptance and expectation of gender egalitarianism is generally related to individualistic and low power distance cultures; however, there are societies of this type with a stronger role division between genders (Maleki and de Jong 2014). Unity between humans and nature is emphasized in the Asian societies (Aoyagi-Usui et al. 2003; Wang and Huang 2016), while concern for the environment is accentuated in the countries of Western Europe such as Sweden (Schwartz 2004). The Swedish culture considers alignment with the world as important while not trying to change it, and to relate to others as equals (Ibid.). The human-nature unity implies that there are no clear distinctions between humans and nature and thus, nature is not against humans (Bruun and Kalland 2013; Aoyagi-Usui et al. 2003). However, as Bruun and Kalland (2013) argue, there is a diversity within what is described as Asian and Western values or perceptions, and perceptions such as people's attitudes to nature are dynamic entities.

Another aspect of importance for the value systems in a society is the level of economic development (Hofstede and McCrae 2004; Inglehart and Oyserman 2004; Schwartz 2004). According to Schwartz (2004), socioeconomic and cultural variables have strong influence on each another as culture can mediate the effects of socioeconomic variables on the behavior of individuals. Socioeconomic indicators such as high levels of average income and high levels of education are positively correlated with cultural egalitarianism and autonomy (Ibid.). The nations in the East Asian region have traveled different paths toward modernization and economic development, some more recently than others. Therefore, there are variations between the countries within the region (Zhang et al. 2005; Lin and Ho 2009). Taiwan has gone through rapid economic development during recent decades (Zhang et al. 2005; Lin and Ho 2009; Tsai 2012), beginning in the 1950s (Chow and 
Lin 2002). Taiwan has adopted the European and North American notions of democracy and modernization, which has resulted in some intertwinement of western and traditional Chinese cultures in Taiwan (Yu et al. 2019). Sweden experienced long-term and relatively stable growth in its economy, from the mid 19th century and onwards (Ljungberg and Nilsson 2009).

The literature review above highlights some variations between Taiwanese and Swedish culture. Based on the research reported herein, we would assume that differences exist in the sustainability consciousness (SC) of Taiwanese and Swedish students. In the next paragraph, we define the concept of SC and identify some relationships between values and the attitudinal, behavioral and cognitive sub-constructs that form the composite construct of SC.

\subsection{The concept of sustainability consciousness}

The concept of SC unifies the content in the environmental, social and economic dimensions and the psychological constructs of knowingness, attitudes and behaviors relating to such issues. The concept of SC was originally developed to study the effects of the ESD implementation in Swedish schools at the student level. SC is operationalized into a survey instrument in which each item measures either knowingness, attitudes or behaviors in relation to one of the environmental, social or economic dimensions of SD (Berglund et al. 2014; Olsson et al. 2016). The items are based upon definitions of the dimensions found in UNESCO (2006, pp. 18-21).

\subsubsection{Sustainability knowingness, attitudes and behaviors}

Knowingness in relation to SC reflects an awareness of the theoretical components of SD. The items that build up the knowingness part are not intended to probe factual knowledge about environmental, economic and social issues. Therefore, knowingness is regarded a suitable denotation of the construct (Berglund et al. 2014). Attitudes have cognitive, emotional and behavioral components; however, the knowledge component is in many situations limited when people make attitudinal judgments (Murray 2011; Eagly and Chaiken 1993). Attitudes express individual values and beliefs (Murray 2011) and determine one's reaction to a situation, an object or other people (Eagly and Chaiken 1993; Kollmuss and Agyeman 2002; Murray 2011). However, attitudes alone do not predict behavior (Kollmuss and Agyeman 2002; Murray 2011). Instead, many factors interact in complex ways to form individual behaviors.

Barriers that impede pro-environmental behaviors have been described by Gifford (2011). One barrier to action may be ignorance; either not being aware of a problem, or lack of knowledge concerning how to deal with it (Kennedy et al. 2009; Gifford 2011). Another barrier may be numbness, which may arise because of receiving too many messages of the same kind about environmental problems. Moreover, individuals may consider that action is pointless because the impact is too small in the bigger picture. This also relates to social norms; people may alter their behavior if they find out that they do something that deviates from what others around them do (Gifford 2011). Conflicting values at the individual level may be another constraint and in this case, environmental values tend to be downgraded (Gifford 2011; Kennedy et al. 2009). These barriers may partly explain the gap between pro-environmental attitudes and pro-environmental behaviors, a subject that has been extensively discussed in research (e.g., Kollmuss and Agyeman 2002; Schultz 
et al. 2005; Meinhold and Malkus 2005; Kennedy et al. 2009; Boeve-de Pauw and Van Petegem 2011a; Wang 2016).

Aoyagi-Usui et al. (2003) found that the structure of environmental values differed between Asian and Western countries, and so did the factors encouraging environmental behaviors. In the Asian countries, an environmental way of thinking was regarded as being in line with traditional values, whereas people in Western countries viewed environmental concepts as contradictory to their traditional values. Boeve-de Pauw and Van Petegem (2011a) identified cultural differences in children's environmental values, environmental behaviors, and the ways environmental values and behaviors were interrelated.

In Taiwan, Fang et al. (2018) found environmental knowledge to be negatively correlated with environmental attitude among university students, but positively correlated with environmental behavioral intention although the correlation was weak. Moreover, environmental attitude was positively correlated with environmental behavioral intention. Within the environmental dimension, Liang et al. (2018) found no significant correlations between knowledge and attitudes or between knowledge and behavior among undergraduate students in Taiwan. The level of environmental knowledge and behavior among the students was found to be relatively low, while the level of environmental attitude was moderate. However, a higher level of environmental knowledge was found to correlate significantly with a higher level of both attitude and behavior. Research from the Western European context indicates that compared to students from other cultural contexts, Western European students show the lowest correlation between environmental values and pro-environmental behavior (Boeve-de Pauw and Van Petegem 2011b). A study by Kramming (2017) indicated that Swedish upper secondary students perceive cognitive dissonance between knowing what is right and doing what is required in relation to environmental challenges. The students expressed a gap between a collective approach, which they considered as necessary, and the possibilities they themselves experienced they had to contribute to such an approach. A recent study from Greece indicated three factors of importance in the interpretation of students' behavior; school and family role toward environmental conscience, students' degree of environmental conscience, and students' degree of environmental education (Ntanos et al. 2018).

To summarize, culture influences the ways in which the environment is viewed and lived in (Commonwealth Secretariat 2007). It influences the views on what development means, how people act in the world and the various attitudes, worldviews and practices of people. Based on this, we assume that it is possible to detect whether a cultural distinctness exists in relation to SD among young people in Taiwan and Sweden through the SC construct. Since aspects of the cultural value orientations are diverse and point in different directions, it is impossible to predict the directions that these may influence the SC of the two groups of students. Instead of doing that, this study aims to identify if there are differences and if so, in what ways these are manifested and what implications for ESD this may have.

\subsection{Environmental and sustainability education in Taiwan and Sweden}

In addition to cultural factors, another relevant area to consider is the educational background and experiences of the students, in relation to the topic of investigation. In this way, the results of this study may partly depend on but also have implications for the environmental and sustainability education taking place in Taiwan and Sweden. In many descriptions, environmental education focuses on concern for the natural environment, whereas ESD should take into account the interconnections between the environment and social 
and economic development, however, there are different ways of viewing this (McKeown and Hopkins 2003). In general, ESD departs from the supposition that solutions to environmental problems should be based on social and economic incentives. Historically, education has evolved from having an environmental focus into having a sustainability focus, although both perspectives coexist within education (Sandell and Öhman 2010).

For several decades, education has been highlighted as an important agent in the transformation of society toward SD. In 2002, the United Nations General Assembly declared the years 2005-2014 to be the UN Decade of Education for Sustainable Development (UNDESD). The overall vision of the UNDESD was for people to "learn the values, behavior and lifestyles required for a sustainable future and for positive societal transformation" (UNESCO 2006, p. 24). At the end of the UNDESD in late 2014, new directives and guidelines for future development were provided in the Global Action Programme, GAP (UNESCO 2014). The GAP states that one goal of ESD is "to reorient education and learning so that everyone has the opportunity to acquire the knowledge, skills, values and attitudes that empower them to contribute to sustainable development" (p. 14). The following paragraphs outline the establishment and framing of environmental and sustainability education in Taiwanese and Swedish curricula.

\subsubsection{Taiwan}

In 1992, the document "Essential components of Environmental Education" was published by the Division of Environmental Protection Administration Executive Yuan in Taiwan, which stipulated that secondary schools should develop students' critical thinking and evaluation abilities, and stimulate environmentally friendly behaviors among students (John et al. 2013). However, until 1998, there was nothing stated in the Taiwanese curriculum about the implementation of environmental education, although schools were encouraged to carry it out (Yueh and Barker 2011). The Taiwanese curriculum was revised in 1998, and since then, six important issues of which environmental education is one are required to be incorporated into seven key learning areas (social studies, mathematics, integrative activities, language arts, arts and humanities, health and physical education and science and technology) (Yueh and Barker 2011). During the last 20 years, five graduate institutes of environmental education were established in different parts of Taiwan. Later on, environmental learning centers were established that facilitated environmental learning activities (John et al. 2013). In 1999, the Graduate Institute of Environmental Education at the National Taiwan Normal University initiated the Green School Partnership Project, which by 2013 included nearly 3700 schools in Taiwan (Ibid.). The Taiwan Sustainable Campus Program was launched in 2004, based on the three components: campus ecology, environmental management and sustainable technology. The initiative was intended to impact on the curriculum; however, it has been shown to have little impact on how teaching is carried out (Ibid.).

The Sustainable development policy guidelines were formulated in 2009 by the National Council for Sustainable Development in Taiwan. The guidelines highlighted the expansion of sustainable development education (Tsai 2012). In 2011, the Environmental Education Act was enacted, stating that students and teachers in elementary and secondary schools in Taiwan should participate in an environmental education program annually (Liu et al. 2015). Yueh and Barker (2011) found that teachers in Taiwan, to a large extent, practiced subject thinking in their teaching at the expense of overarching aims, vision statements and 
core competencies. The findings indicated very little support for curricular integration of environmental perspectives.

A large-scale nationwide study by Liu et al. (2015) indicated a need for increasing inservice teachers' understanding of global environmental issues. Findings from the same study indicated a risk that environmental education occurs less frequently in high school compared to elementary school and that a majority of the teachers had not included environmental learning activities into their teaching. According to John et al. (2013), teachers in Taiwan experience overloaded curricula and time constraints, which result in marginalization of environmental and sustainability education. A search through the field of environmental and sustainability education research indicated that there seem to be few studies from Taiwan including elementary or secondary students, at least that are available for the international research community. Studies commonly focus on university students or teachers. However, a recent study indicated that students in Taiwan considered that the ESD approach increased the relevance of their learning content (Laurie et al. 2016). They also reported learning the values for SD, and that ESD had encouraged the use of innovative methods and teaching approaches as positive outcomes (Ibid.).

\subsubsection{Sweden}

In Sweden, ESD has grown out of environmental education, which was introduced into the school curriculum as early as the 1960s. In the 1980s, environmental education was formally introduced into the subjects of natural sciences, and during the early 1990s, Sweden joined Agenda 21 together with many other countries (Cars and West 2015). During the 1990s, ESD was promoted at national level and ESD-based approaches began to influence environmental education (Breiting and Wickenberg 2010). Different teaching traditions have been shown to coexist within the scope of environmental education in Sweden (Öhman 2008). Nowadays, a holistic and pluralistic approach to environmental education is often synonymous with ESD in Sweden. A recent study found that students who experienced pluralistic teaching approaches to higher extent reported a higher level of sustainability behaviors (Boeve-de Pauw et al. 2015). In this context, pluralism implies encouraging the development and critical analysis of different perspectives embedded in sustainability issues, and hence, avoiding the teaching of pre-defined solutions. However, the same study indicated that Swedish students generally did not experience pluralistic approaches in teaching to any substantial extent, although upper secondary students reported more occurrence than did compulsory school students (Boeve-de Pauw et al. 2015).

Since 2008, the Swedish International Center of Education for Sustainable Development (SWEDESD) has supported ESD practice in Sweden through networking, training and research and policy development. There are also a number of both governmental and non-governmental initiatives supporting schools in their ESD implementation. Examples are the international program "Eco-schools" (Keep Sweden Tidy 2017), and the "School for sustainable development" award (The Swedish National Agency for Education 2017).

In 2011, a new curriculum was launched in Sweden, in which SD was identified among the fundamental values and tasks for every school and addressed as a topic that should permeate all subjects (The Swedish National Agency for Education 2011a, b; Laurie et al. 2016). Moreover, SD is advanced in the syllabuses of many subjects. The new curriculum highlights competencies that schools and teachers should strive to develop among their students. These competencies include critical thinking, problem solving and democratic action competence, which are often emphasized in the ESD discourse (see, e.g., Mogensen 
and Schnack 2010; Öhman 2008; Vare and Scott 2007; Yueh and Barker 2011; UNESCO 2014).

A large-scale study on upper secondary teachers in Sweden indicated that many teachers hold positive attitudes to, and awareness of, sustainability as central to their subject-discipline (Borg et al. 2012). However, the study indicated that many teachers feel underprepared to teach sustainability-related issues, and it was further shown that the teachers understood SD in different ways (Borg et al. 2014). Furthermore, interdisciplinary work related to SD as a way to fulfill curriculum demands seldom occurred, and the teachers experienced time constraints, impeding their opportunities to change their teaching toward ESD. Barriers were generally related to a subject-discipline focus among the teachers. Borg et al. (2012) concluded that establishing conditions that favor interdisciplinary work and collaboration among teachers is an important step, which they regarded as a responsibility of the school management (see also Laurie et al. 2016). The study by Laurie and colleagues indicated that not only students in Taiwan, but also students in Sweden, find that the ESD approach increases the relevance of their learning content. In addition, ESD perspectives increase Swedish students' influence on their education, help to develop systems thinking and problem-solving skills, and foster respect for humans and nature (Ibid.).

\subsubsection{Similarities and differences}

A common feature of the secondary education in Taiwan and Sweden seems to be a prevailing subject focus that creates barriers for implementing environmental and sustainability education as a cross-curricular perspective. Environmental and sustainability education has had a longer history in the Swedish education system than in its Taiwanese counterpart. The mid-decade review pointed out the significance of a strong history in environmental education for the established meaning of ESD (UNESCO 2009, pp. 29-30). The emergence of environmental education during recent decades in Taiwan has resulted in a parallel focus on environmental education and ESD, and therefore, the term environmental education for SD is sometimes used in Taiwan (UNESCO 2009, pp. 29-30). As a consequence of the longer history, it is possible that environmental and sustainability education may have had a broader impact on the Swedish curriculum and the ways it is being delivered, which may have influenced students' learning about sustainability issues and possibly also students' SC. The study by Laurie et al. (2016) included both Taiwan and Sweden, and the findings indicated that ESD has led to innovative approaches to teaching in both contexts. However, despite being visible in the curricula of both Taiwan and Sweden, a broader transformation of teaching practices to meet ESD demands still has not occurred in either country. Based on the literature review, we find support for the premise that differences in Taiwanese and Swedish students' SC may exist due to cultural as well as educational differences within the two countries.

\subsection{Aim and research questions}

As we have pointed out, culture is important for the ways that SD is enacted in different parts of the world. Respect for cultural diversity is an important value in ESD, and culture is assumed to influence ESD practices around the world. However, not much is said in international ESD policies about how this can be done, and cross-cultural studies are lacking (Kopnina and Meijers 2013). The cultural as well as the educational context and the history of environmental and sustainability education in Taiwan and Sweden share some 
aspects and diverge with respect to others. In order to meet the need to study expressions of SD in light of different cultural and educational contexts, the current research aims to investigate and compare the SC of grade 12 students in Taiwan and Sweden. An additional aim is to discuss implications of possible differences for SD and ESD policy and practice.

The research questions in focus are:

- Are there differences in the sustainability consciousness of Swedish and Taiwanese upper secondary students?

- If so, in what aspects, in terms of knowingness, attitudes and behaviors?

The results of this study will indicate whether there are differences between the two different cultural contexts concerning these sustainability-related aspects. In the discussion, we consider the implications for ESD.

\section{Method}

This study is based on a quantitative approach to investigate whether there are differences in the SC of Taiwanese and Swedish young people. Students aged 18-19 years took part in a survey based on three sub-constructs measuring the sustainability knowingness, attitudes and behaviors of the students. The two student samples were selected to be comparable. The data were collected in 2013 and statistically analyzed. The questionnaire, the sampling and data collection process and the statistical data analysis are described in detail in the following sections.

\subsection{Survey instrument}

The questionnaire used in this study was originally developed in 2013 and used in studies designed to investigate effects of the implementation of ESD in the Swedish school system (Berglund et al. 2014; Olsson et al. 2016). The original questionnaire included 50 items building up the construct of SC. Recently, a shorter version of 27 items was compiled, which was used for the current study, see Notes at the end of the paper. The full questionnaire, its theoretical foundations, and the development and validation process are described in detail by Gericke et al. (2019).

Before the collection of Taiwanese data, standard procedures of translation and back translation were performed. The questionnaire was translated from Swedish into English by a professional language translator and translated back again by another. The English version was then translated into Mandarin by a native speaker researcher and thereafter translated back into English by another.

Each item in the questionnaire relates to a specific sub-theme within the UNESCO (2006, pp. 18-21) definition of the environmental, social and economic dimensions of SD. Each construct of knowingness, attitudes and behaviors includes nine items, each one relating to the environmental (three items), social (three items) or economic (three items) dimension, (see Table 2). The knowingness section focuses on what the respondents regard as necessary constituents for SD. The attitude items are stated either in the form "I think that...," or "I think it is important that...," and thus, the scale reveals positive or negative feelings or judgments toward the phenomena or objects in focus. The behavior section focuses on the students' experiences of what they do or how they act, 
i.e., their self-reported behavior. For every item, there is a five-point Likert scale, ranging from Strongly disagree to Strongly agree, and a Don't know-option (see also Berglund et al. 2014; Gericke et al. 2019).

To test the model, a series of confirmatory factor analyses (CFA) were performed, using both the Swedish and Taiwanese samples. To test the construct validity of the SC questionnaire (SCQ), we fitted the model behind the SCQ-Short version as described in Gericke et al. (2019) to the data from the current study (including both samples). Initial fit statistics indicate reasonable model fit with $\mathrm{RMSEA}=0.07, \mathrm{CFI}=.91 \& \mathrm{TLI}=.90$ ). The inclusion of several error covariances (based on estimates of the modification index) showed the robustness of the model to measure the SC of grade 12 students validly in Sweden and Taiwan $(\mathrm{RMSEA}=0.06, \mathrm{CFI}=.94 \& \mathrm{TLI}=.93)$.

\subsection{Sampling and data collection}

The aim of this study was to investigate whether there are differences in the SC of Taiwanese and Swedish young people and if differences do exist, to look more deeply into their characteristics. The analysis included two main groups of students (age 18-19), one from nine different senior secondary schools across Taiwan and one from 15 different upper secondary schools across Sweden. In total, 672 students from Taiwan and 638 students from Sweden took part in completing the survey. The whole sample included students from schools with a Green or ESD school profile (denoted the ESD group of students) and students from schools without such a profile (denoted the reference [REF] group of students), for both samples. The reference group of students was selected to match the Green school-/ ESD-student sample with respect to a number of criteria (Berglund et al. 2014; Olsson et al. 2019). Accordingly, the Taiwanese and Swedish samples were matched to be comparable, but they were not randomly selected, thus affecting the generalizability of the results. The focus of the study is on cross-cultural differences, and the samples are considered to illuminate such differences. However, the findings of this study are not and are not intended to be, representative of the two countries included in this study. Moreover, differences between ESD- and REF-school students are addressed in other studies and are not the focus of the present study. Within the Taiwanese context, Olsson et al. (2019) investigated the differences between Green school students and students from REF schools by using the SC questionnaire. Within the Swedish context, Berglund et al. (2014) and Olsson et al. (2016) have investigated the differences between students in schools with an explicit ESD profile and schools without such profile.

An overview of the sample composition is provided in Table 1. There was a larger proportion of female students in both samples but especially in Taiwan. Social science

Table 1 Overview of the sample

\begin{tabular}{lllll}
\hline & & ESD/REF & Female/male & $\begin{array}{l}\text { Science/ } \\
\text { social sci- } \\
\text { ence }\end{array}$ \\
\hline Taiwan & 617 & $273 / 344$ & $393 / 224$ & $212 / 405$ \\
Sweden & 583 & $371 / 212$ & $328 / 255$ & $332 / 251$ \\
\hline
\end{tabular}

The first column shows the number of students included in the analysis, and the numbers in the other three columns show the distribution of students within the different sub-groups 
students were overrepresented in the Taiwanese sample and underrepresented in the Swedish sample. These factors were included in the analysis in order to assess their influence. This is described further in the next section.

The Swedish data were collected during spring 2013 by one of the researchers or a colleague visiting the schools during ordinary school hours (with one exception where it was impossible to get access to the selected classes on the same day). The majority of students present in the classroom accepted to participate, and their questionnaires were completed and returned successfully (93\%). A few students experienced computer problems with sending in their response and they did not want to start the survey all over again. In the Swedish sample, eight out of 15 schools had an ESD profile. For a thorough description of the data collection process, (see Berglund et al. 2014).

The data collection in Taiwan took place in late autumn 2013. The sampling of Green/ non-Green schools in Taiwan considered a geographical balance, and the schools in the sample represent the northern, central and southern areas in Taiwan. The schools are all urban, due to the situation in Taiwan where there are relatively few Green schools, and a relatively small proportion of students from rural areas. Two classes from each school were randomly selected in order to align with the Swedish sampling. However, the number of Swedish students from each school varied more than intended (see Berglund et al. 2014). The ratio of ESD/REF students in the Taiwanese sample indicates the low participation of 12th graders in the Green school Partnership Program. In the Taiwanese sample, four out of nine schools were Green schools. Thus, the number of REF students was larger, in contrast to the Swedish sample in which eight out of fifteen schools were ESD schools. One of the schools in the Taiwanese sample was a girls' high school, which contribute to the larger proportion of girls. The overrepresentation of social science students is a consequence of the uneven gender distribution, since female students in Taiwan are overrepresented within the social sciences. The data collection process took about two months to complete and it followed the ethical guidelines and regulations of each country, respectively.

\subsection{Data analysis}

The results are based on multivariate analysis of variance, followed by the univariate test results (MANOVA/ANOVA). MANOVA is a statistical test that allows for analysis of differences in means between groups when there is more than one dependent variable. In our case, there are three dependent variables, the sub-constructs of sustainability knowingness (sustainability_K), sustainability attitudes (sustainability_A) and sustainability behaviors (sustainability_B). In our analysis, we allowed for $25 \%$ missing data (including the "Don't know" option) of each respondent's answer within each of the three sub-constructs. The MANOVA accounts for correlations between dependent variables (Field 2013). In this case, Pearson's correlations between all combinations of the constructs were all significant at the level $p<.001$ for both samples and ranged between 0.406 and 0.655 . If significant differences are found in the multivariate analysis, the univariate results will indicate whether differences are also present in any of the underlying constructs.

In MANOVA, the effects of variables that are not the focus of the comparison, but that may still have an influence, can be accounted for (Hair et al. 2006). The additional variables which were included as factors in our analysis were gender (female/male), school program (science/social science) and school category (ESD/REF). By including these in the analysis, we are able to establish that significant differences were not the result of different compositions of the two samples with respect to these sub-groups. The significance 
level for all analyses was set to $p<0.05$. Calculations of the effect size (Cohen's $d$ ) were undertaken to ensure practical significance in addition to the statistical significance (Hair et al. 2006). The Cohen's $d$ is usually regarded as being small if $0.2 \leq d<0.5$, medium if $0.5 \leq d<0.8$, and large if $d \geq 0.8$ (Cohen 1992).

\section{Results}

This section starts with some descriptive statistics, which are then used in the interpretation and discussion of the results from the multivariate/univariate analysis. The results from the multivariate/univariate analysis are presented thereafter, corresponding to the two questions posed in the introduction.

Table 2 shows the 27 items used in this study with means and standard deviations for both samples. Results from the reliability analysis of the SC construct as well as its subconstructs are provided in terms of Cronbach's $\alpha$. The analysis indicated sufficient reliability of the instrument with alphas above 0.7 for all constructs, which is commonly regarded as the threshold for satisfactory reliability (Field 2013). The means and standard deviations in Table 2 represent pure in-data, which implies that the influence of other variables that we do not focus on in this study is not accounted for. However, comparing results of multivariate/univariate analysis with and without including the factors of ESD/REF students, female/male students, and science/social science students, indicated very small differences between the estimated marginal means for each country, respectively (generally about the size of a few centesimal). The Swedish data indicated some ceiling effects related to the battery of attitude items, which results in lower variance for the Swedish sample. The presence of ceiling effects in attitude measurements has been discussed in several studies, e.g., Dunlap et al. (2000), Spence and Hahn (1997), Boeve-de Pauw et al. 2014). Moreover, homogeneity of variance-covariance tests for large samples often indicate statistical significance even if the differences may be extremely small and lack practical significance (Hair et al. 2010). Therefore, homogeneity of variance was considered satisfactory at the level of $p<0.01$. The construct of sustainability behaviors still indicated a significant difference at this level. However, this was considered to lack practical significance as the variance for sustainability behaviors compared to the variance for sustainability knowingness (which was nonsignificant) was negligible (see standard deviations in Table 3). However, the Pillai's trace test statistic was considered the most suitable due to its robustness under these conditions (Field 2013).

\subsection{The sustainability consciousness of Taiwanese and Swedish students}

Using Pillai's trace, the multivariate analysis indicated a significant difference between the Taiwanese and Swedish samples in their SC $(V=.362, F(3,1182)=223.622, p<.001$, partial $\left.\eta^{2}=.362\right)$. A significant interaction effect was found between the variables for country and gender, indicating that both variables are needed to explain the result $(V=.018$, $F(3,1182)=7.070, p<.001$, partial $\left.\eta^{2}=.018\right)$. A deeper look revealed larger differences between Taiwanese and Swedish females than between males for the constructs of Sustainability_K and Sustainability_A, and larger differences between Taiwanese and Swedish males than between females for Sustainability_B. Females had higher means for all three constructs in both countries, with the exception of Sustainability_K in Taiwan, where males had a slightly higher mean. The interaction effect is shown in Fig. 1. 


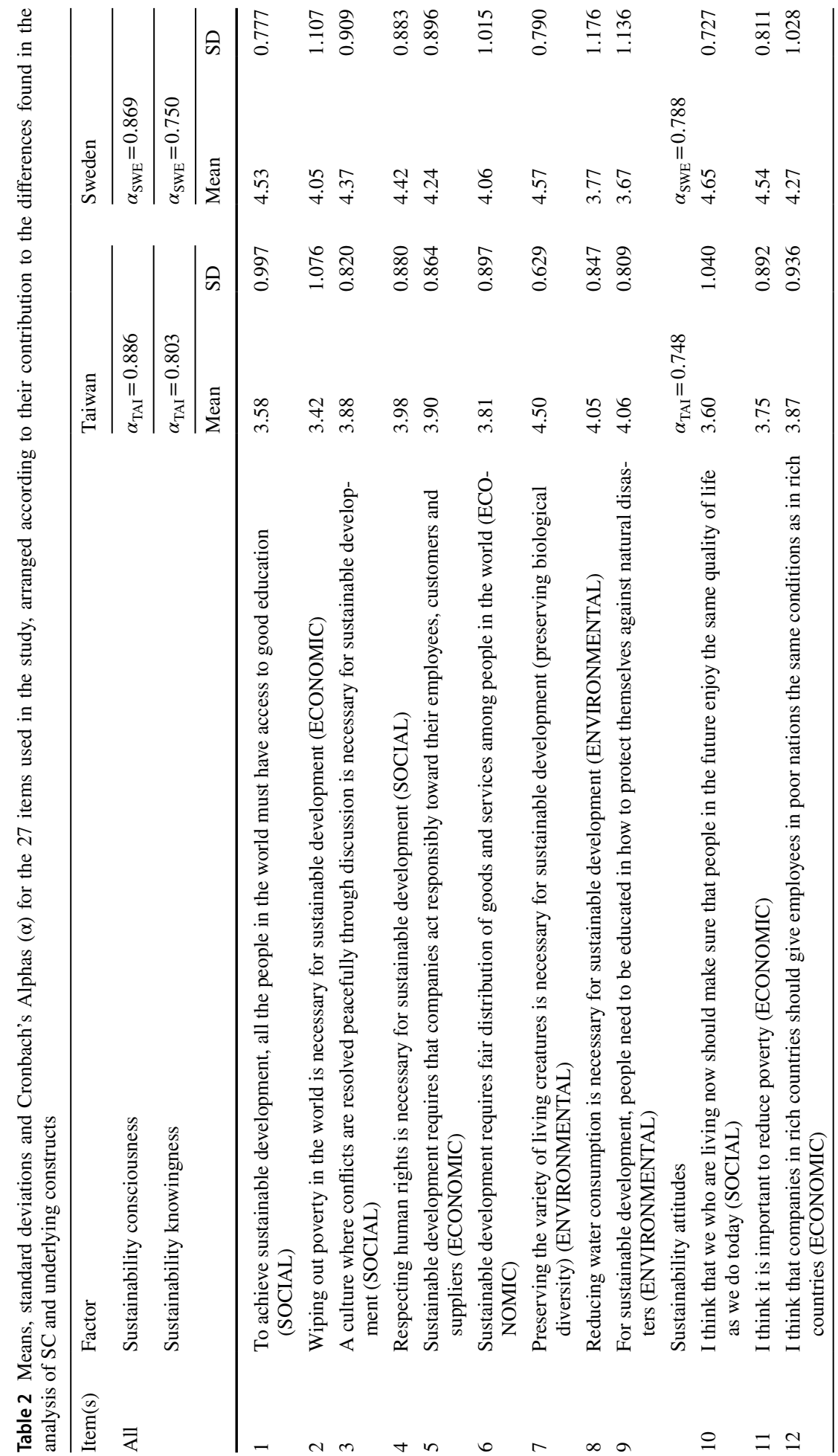




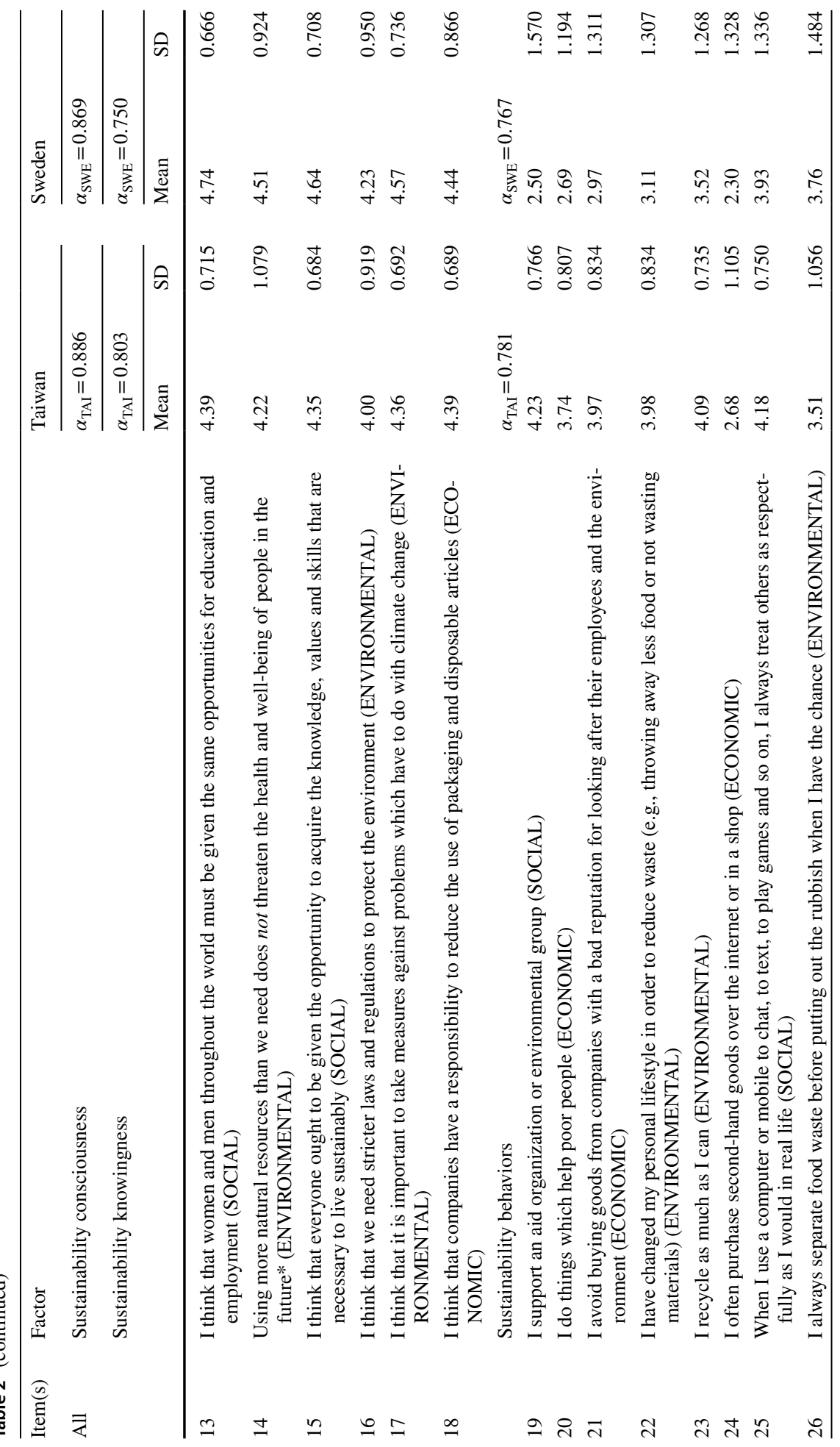




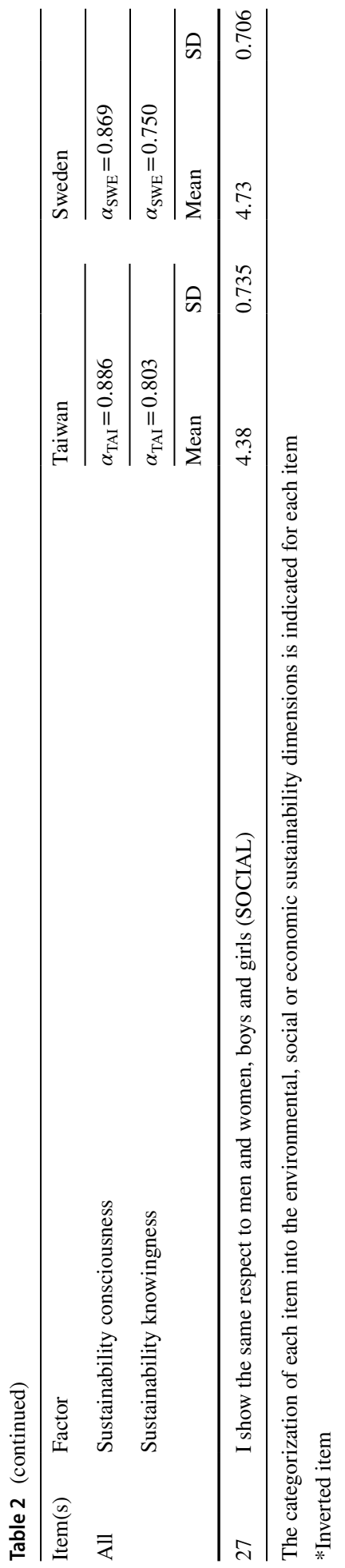


Table 3 Univariate results for the sub-constructs of SC

\begin{tabular}{|c|c|c|c|c|c|}
\hline & \multicolumn{2}{|c|}{ Taiwan } & \multicolumn{2}{|c|}{ Sweden } & \multirow[t]{2}{*}{ Effect size } \\
\hline & Mean & SD & Mean & SD & \\
\hline Sustainability_K & 3.936 & 0.720 & 4.177 & 0.579 & 0.369 \\
\hline Sustainability_A & 4.128 & 0.646 & 4.491 & 0.531 & 0.614 \\
\hline Sustainability_B & 3.892 & 0.795 & 3.232 & 0.652 & 0.908 \\
\hline
\end{tabular}

The two means for each of the sub-constructs were significantly different at the level of $p<0.001$. The effect size is indicated by Cohen's $d$
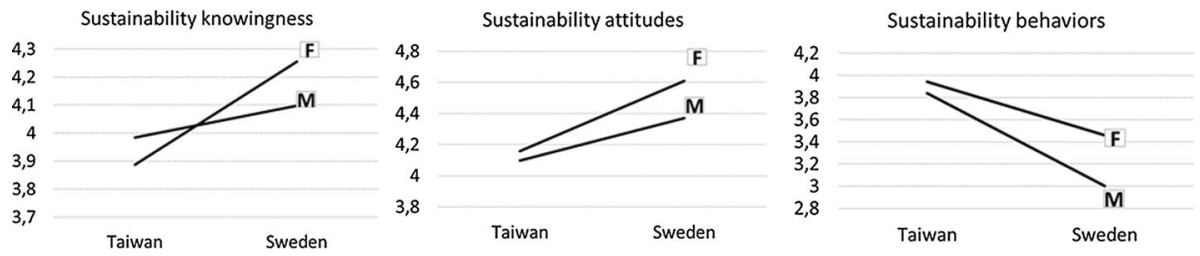

Fig. 1 Interaction effect between the variables of country and gender (F, M) for the three constructs of sustainability knowingness, sustainability attitudes and sustainability behaviors (note the scale differences of the vertical axis)

Fig. 2 Means for Taiwanese and Swedish students within each sub-construct of SC $(* p<0.001)$

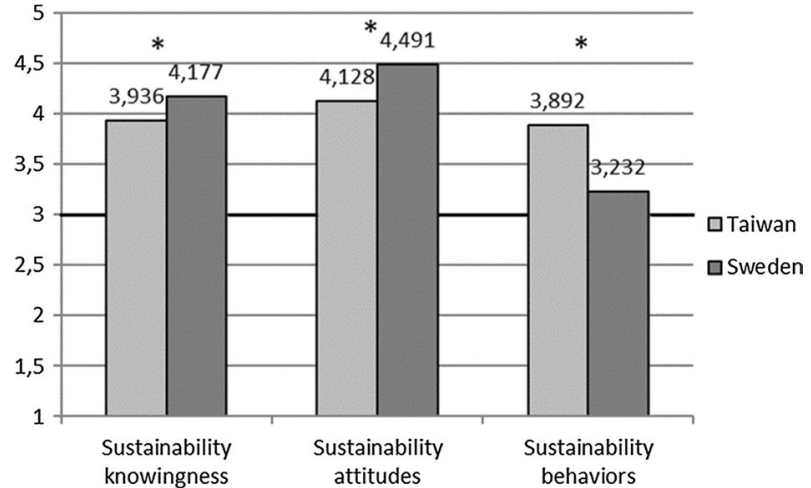

In order to analyze the differences further, the univariate results are shown below. Figure 2 and Table 3 indicate means and standard deviations for the underlying constructs of Sustainability_K, Sustainability_A and Sustainability_B for the two groups of students. The dark line indicating the value of 3 in Fig. 2 marks the division between agreement and disagreement on the scale used for the items. This implies that the farther above the line, the stronger the general agreement, and the farther below the line, the stronger the general disagreement. All means are above the line and thus indicate general agreement; however, the sustainability behavior among students in Sweden is not far above a neutral 3. Table 2 indicates the contribution of each item to the lower sustainability behaviors among students in Sweden.

Figure 2 shows that there were significant differences between the two samples within all three sub-constructs of SC: Sustainability_K: $F(1,1184)=41.410, p<.001$; Sustainability_A: $F(1,1184)=115.780, p<.001$; Sustainability_B: $F(1,1184)=255.054$, 
$p<.001$. Swedish students demonstrated higher means for sustainability knowingness and attitudes, whereas Taiwanese students demonstrated higher means for sustainability behaviors. Table 3 indicates the effect sizes, which were small for sustainability_K, medium for sustainability_A and large for sustainability_B.

\section{Discussion}

The main purpose of this study was to investigate the SC of grade 12 students in Taiwan and Sweden and thus, contribute knowledge to the discussion about the shape and character of SD and ESD in different cultural contexts, an area where more knowledge and research is needed. At international policy level, the importance of cultural diversity is emphasized, and expressions of SD and ESD are encouraged to take different shapes to adapt to the cultural context. This study investigated the broader consciousness of SD among students in Taiwan and Sweden, two countries that differ in cultural and educational history and context. The Study framework section outlined some aspects of the value orientations of the two regions, in terms of collectivism/individualism, hierarchy/egalitarianism (power distance) and harmony/mastery. In addition, the educational contexts of Taiwan and Sweden were briefly described, indicating that the implementation of environmental and sustainability education as a cross-curricular perspective is a common struggle. However, environmental and sustainability education has had a longer history in the Swedish education system, which can be assumed to have influenced the current meaning of ESD (UNESCO 2009, pp. 29-30). Nevertheless, previous research has indicated the need for Swedish as well as Taiwanese teachers to develop their knowledge and teaching practice in relation to environmental and sustainability issues.

Based on the cultural and educational history and character, we expected to find differences in the SC between Taiwanese and Swedish students. The results showed that significant differences did exist between the two student samples. Further analysis indicated that significant differences existed in all three sub-constructs of SC: sustainability knowingness, sustainability attitudes and sustainability behaviors. The results indicated stronger knowingness and attitudes among the Swedish students. However, this was not associated with stronger behaviors. On the contrary, Taiwanese students showed significantly stronger sustainability behaviors despite significantly lower mean values for knowingness and attitudes. The differences between the two samples were the largest in terms of behaviors and the smallest in terms of knowingness. The findings support previous research, suggesting that the relationships between environmental attitudes or environmental values and behaviors are culture-specific (Aoyagi-Usui et al. 2003; Boeve-de Pauw and Van Petegem 2011a).

The main findings of this study indicated that this is also true for the broader sustainability context. Within the environmental dimension, Boeve-de Pauw and Van Petegem (2011a) concluded that, independently of cultural background, individuals with higher preservation values exhibit more pro-environmental behaviors, while the role of utilization values in predicting pro-environmental behaviors differs across cultures. Boeve-de Pauw and Van Petegem (2011a) suggest using instruments that are able to capture other types of pro-environmental behaviors (e.g., environmental activism, consumer behaviors, non-activist political behaviors, etc.) in future research into cultural differences. From this perspective, this study may contribute with important knowledge since our instrument included self-reported behaviors connecting to those aspects. Findings by Aoyagi-Usui 
et al. (2003) indicated that, in Asia, links existed between an environmental way of thinking and altruistic values, which conflated with traditional values such as family security and honoring parents. People in Western countries also indicated connections between environmental concepts and altruistic values. However, they were perceived as being in conflict with traditional values. This has implications for the uniformly formulated valuerelated goals often emphasized in ESD policy and discourse. According to Aoyagi-Usui et al. (2003), the predictors of environmental behaviors differ between the Asian and Western contexts, which the results of the current study also suggest.

As described in the Study framework section of this paper, many factors interact in shaping human behaviors. The fact that the relationships between knowingness, attitudes and behaviors take different shapes for the two samples in this study gives further support for the UNESCO guidelines directing ESD to be framed according to the cultural context where it takes place. As Fig. 2 showed the gap between attitudes and behaviors was smaller among the Taiwanese students than among the Swedish students. In the study by Fang et al. (2018), the correlation between environmental knowledge and behavioral intention was extremely weak for Taiwanese university students, but there was a correlation between environmental attitude and behavioral intention. Fang et al. question the focus on knowledge transfer in education as the only way to increase environmental action. Liang et al. (2018) found that a high level of environmental knowledge was required if environmental attitude and pro-environmental behavior should be strong. This could be part of an explanation to the finding that sustainability attitude was lower among the Taiwanese compared to Swedish students. Boeve-de Pauw and Van Petegem (2011b) found that the relationship between preservation values and pro-environmental behavior was lower for Flemish pupils as compared to Vietnamese and Guatemalan pupils. This could possibly be the case for the correlation between environmental attitude and behavior, which might extend to the broader sustainability context, as the results of our study indicate. In the more individualistic Swedish society, the perceived cognitive dissonance between knowing what is right and doing the necessary changes at collective level may be stronger, as suggested from the findings by Kramming (2017). The mean difference between the Taiwanese and Swedish samples for sustainability behaviors is close to 0.7 , a substantial difference on a scale ranging between 1 and 5, for which most responses are found within a smaller part of the scale (the upper half). The stronger knowingness and attitudes and weaker behaviors for the Swedish students compared to Taiwanese students give further support for the criticism of simplistic interpretations concerning causal relationships between knowledge, attitudes and behaviors (e.g., Kollmuss and Agyeman 2002; Booth 2009; Michalos et al. 2012; Fang et al. 2018; Liang et al. 2018).

Many factors that contribute to forming individual behaviors within the environmental and sustainability context have been identified in research, for example conflicting values at the individual level and social norms (Gifford 2011), external factors, such as socioeconomic and cultural factors, and internal factors such as motivation, knowledge and values (Kollmuss and Agyeman 2002). However, the interactions between these are complex and difficult to model (Kollmuss and Agyeman 2002). The results of this study suggest that ignorance as a barrier to action (Gifford 2011) seems not to be the case here, as Swedish students responses resulted in significantly higher means for knowingness. However, the effect size was small, and thus, the significance of this difference should not be overinterpreted. Moreover, the context has significance for how individuals act in the field of sustainability (Rauch 2002; Lundegård and Wickman 2009; Berglund and Gericke 2016). Hence, it is difficult to generalize individual actions to any context because of situation specificity related to sustainability dilemmas. Both knowledge and attitudes may contribute 
in shaping individual behaviors, however, many additional factors, for example demographic, economic or other internal factors (see, e.g., Kollmuss and Agyeman 2002, Boevede Pauw et al. 2011c) not included in this study presumably play important roles.

We also found a significant gender-related interaction effect, indicating that gender is of relevance when performing studies in different cultural contexts. A recent study indicated that ESD-profiled schools in Sweden tend to enhance gender differences as the students get older (Olsson and Gericke 2017). The present study shows a general pattern of higher means among females than males, with one exception (Fig. 1). This pattern is generally in line with the findings by Fang et al. (2018), which indicated higher means among Taiwanese female university students for knowledge, attitudes and behavior intention within the environmental dimension. This has also been confirmed for Taiwanese undergraduate students (Liang et al. 2018). Our results indicated stronger knowingness among males than females in the Taiwanese sample, which contradicts the findings by Fang et al. and Liang et al. However, it should be noted that our construct of sustainability knowingness reflects an awareness of the theoretical components of SD rather than factual knowledge about environmental, social and economic issues. These different foci may be an explanation to the discrepancy in findings in this respect. Research from Europe and New Zealand has indicated that females report stronger values in connection to the environmental dimension (Boeve-de Pauw and Van Petegem 2011b; Milfont and Duckitt 2004). However, Boeve-de Pauw et al. (2014) question whether environmental value differences between genders are real value differences, or if they may actually be issues of measurement. Exploring gender differences and related aspects more deeply would require a paper of its own, but could be a focus in forthcoming research.

\subsection{Differences in light of cultural aspects}

The findings of this study suggest that the ways different factors interact in the context of sustainability vary across the two samples. In this section, we discuss the three subconstructs of knowingness, attitudes and self-reported behaviors for the two samples in relation to aspects of cultural value orientations. In addition, we discuss the characteristics of some of the items in our questionnaire that may be of particular relevance in light of the cultural value orientations.

According to Schwartz (2004), people in Sweden strongly emphasize values of egalitarianism. Both egalitarian and hierarchical values aim to maintain the social system through responsible behavior (Ibid.). The difference lies in the way the behavior is grounded; voluntary choice based on internalized engagement is embedded in egalitarianism while conformity to expectations or obligations of assigned roles characterizes hierarchy (Schwartz 2004). The results of this study indicated stronger self-reported behaviors among Taiwanese students. If sustainability behaviors were considered responsible in both contexts, as we may assume, then the stimuli for practicing them may differ. Social expectations or obligations might generate a self-reported wish to act more pro-sustainably as reported by the young people in the Taiwanese sample. However, it remains unclear whether this wish also is expressed in real action, and more research is needed in this respect.

The literature indicates that values of egalitarianism/low power distance are emphasized in Western European culture (e.g., Schwartz 2004; Hofstede and McCrae 2004). Such values may contribute to high means for some of the items in the attitude section for the Swedish sample, e.g., items 11 and 12 concerning poverty reduction and fair conditions among workers in rich and poor countries (Table 2). Values in line with low power distance also 
relate to acceptance and expectation of gender equality according to Maleki and de Jong (2014). However, responses to item no. 27 suggest that gender equality was recognized as important in both contexts. A national focus on gender equality in Taiwan has resulted in a requirement to incorporate gender education into the national 1-12 grade curriculum framework (Ministry of Education 2014).

As described in the Study framework section, concern for the environment is another feature strongly emphasized in Western European societies (Schwartz 2004). Some items in the attitude section of this study actually reflect environmental concerns, e.g., whether we need stricter laws and regulations to protect the environment (No. 16); whether it is important to take measures to combat problems related to climate change (No. 17), etc. As discussed previously, the students in the Swedish sample apparently do less to act according to this deeper value or attitude.

The results for sustainability knowingness showed that the mean for the Swedish sample was significantly higher than the mean for the Taiwanese sample. However, Swedish students showed higher means for all social (No. 1, 3, 4) and economic (No. 2, 5, 6) items, but not for the environmental (No. 7, 8, 9) items (Table 2). In addition, the Taiwanese means were higher for the environmental items in comparison to their responses to social and economic items (Table 2). Research has shown that unity between nature and humans is an important value in Asian cultures (Aoyagi-Usui et al. 2003; Wang and Huang 2016). A possible explanation for the lower means for the social and economic items may be that the Taiwanese students interpreted SD as an environment-related concept to a greater extent than the Swedish students did. This is further discussed in the next section, which focuses on educational aspects.

Yet another aspect that might have relevance is that respondents measure themselves against a social norm, and therefore, answers generally contain a component of social desirability that make respondents agree to a greater extent than is the case for their actual attitudes (Hofstede and McCrae 2004). Perhaps concern for the environment was perceived as a social norm in Sweden, thereby increasing the pressure to agree with the items in the attitude section that related to the aspect of environmental concern. Possibly, the same issues were considered less socially important in Taiwan. In a similar way, the collectivistic value orientation might promote social desirability, which may have influenced the selfreported behaviors aligning with the social norms in Taiwan.

\subsection{Differences in light of educational perspectives}

Responses to some items may vary because of different educational experiences. An example is item no.19, for which the difference between the two samples is extremely large. Taiwanese students reported high agreement, which may be related to successful service education. In Taiwan, engagement in extracurricular activities, such as student societies and non-governmental organizations, is encouraged in senior high schools and influences admissions into higher education (WENR 2016). Thus, the act itself might not reflect a deeper value but rather an external motivation factor. This reasoning is also relevant to item no. 26 for which Swedish students reported a higher mean. In Sweden, many municipalities have constructed physical structures for the separation and management of food waste, which actually make it difficult not to perform these activities. In Taiwan, different policies have been implemented in order to achieve the goal of zero waste (Young et al. 2010). Recycling in Taiwan has been very successful, which is reflected in the high means for items 22 and 23 for the Taiwanese sample. Moreover, during the last fifteen years, 
educational reforms were implemented in schools and in higher education that focused on reducing greenhouse gas and energy conservation (Yu et al. 2019). Sustainable campus projects assisted schools with funding related to, e.g., systems for energy and water saving. The projects facilitated development of curriculum and instruction, and by 2010, the Ministry of Education initiated an education program that emphasized the importance of climate change adaption (Ibid.). Taken together, these actions may form at least part of an explanation to the higher level of sustainability behaviors among the Taiwanese students. However, it seems an internal understanding or feeling of the importance of these actions does not accompany this higher level of reported sustainability behaviors.

Environmental education has a long history in Sweden, which has implications for the meaning of ESD as pointed out in the mid-decade review (UNESCO 2009, pp. 29-30). The Swedish curricula stress SD as a perspective that should permeate all subjects (The Swedish National Agency for Education 2011b). It is possible that the higher mean values for social and economic knowingness among Swedish students reflect an increased awareness of the conceptual underpinnings of SD among Swedish teachers. If so, this may have resulted in more holistic and integrated approaches to environmental, social and economic dimensions of SD in their teaching. However, more research is needed to test this hypothesis.

\subsection{Implications for ESD}

We found significant differences in the SC of Swedish and Taiwanese students. These findings give support to the UNESCO guidelines directing ESD to be framed according to the cultural context where it is implemented. However, little is said in international policies about the ways this should or could be dealt with in education. For example, holistic approaches to SD can be interpreted and handled in different ways. Environmental, social and economic perspectives can be dealt with either from a multidisciplinary or an interdisciplinary perspective, which may result in different learning outcomes [see a discussion in Feng (2012) and Berglund and Gericke (2016)]. Another example is the values-driven nature of ESD, as pointed out in different policies (UNESCO 2006, p. 5; UNESCO 2009, p. 26; UNESCO 2014, p. 14). Recent research from Sweden shows that if students perceive their teaching to be pluralistic, there are positive learning outcomes, mainly connected to their sustainability behaviors (Boeve-de Pauw et al. 2015). Consequently, pluralistic approaches enhance sustainability actions among Swedish students despite (or because of) the open-ended and non-deterministic focus. As the studies by Aoyagi-Usui et al. (2003) and Boeve-de Pauw and Van Petegem (2011a) indicated, the interrelationships between internal factors such as values and individual behaviors differ between cultural contexts. The results of our study suggest that this is true also for the broader sustainability context. However, more research is needed to explore ways to encourage sustainability actions among students in different cultural contexts.

The UNESCO (2009, p. 14) mid-decade review report called for more research in the areas of outcomes, impacts and performance, in order to create evidence-based rather than learning-based processes. This cross-cultural comparative study contributes knowledge to the discussion about the cultural specificity of SD and ESD. Comparative studies of this kind are important to shed light on meanings and interpretations of SD and hence, be a piece of the puzzle concerning the needs, challenges, opportunities and routes for ESD in different parts of the world. 
Notes Web address to the English version of the questionnaire items, http://kau.diva-portal.org/smash/get/ diva2:1356152/FULLTEXT01.pdf.

Acknowledgements Open access funding provided by Karlstad University. A big thanks to Professor Shu$\mathrm{Nu}$ Chang Rundgren. Without your assistance, this research would have been impossible to carry out. We are also grateful to all the schools and students who participated in the study.

Funding The Swedish Research Council [project B0589701] funded this work.

Open Access This article is distributed under the terms of the Creative Commons Attribution 4.0 International License (http://creativecommons.org/licenses/by/4.0/), which permits unrestricted use, distribution, and reproduction in any medium, provided you give appropriate credit to the original author(s) and the source, provide a link to the Creative Commons license, and indicate if changes were made.

\section{References}

Aoyagi-Usui, M., Vinken, H., \& Kuribayashi, A. (2003). Pro-environmental attitudes and behaviors: An international comparison. Human Ecology Review, 10(1), 23-31.

Aşici, A. A. (2013). Economic growth and its impact on environment: A panel data analysis. Ecological Indicators, 24, 324-333.

Berglund, T., \& Gericke, N. (2016). Separated and integrated perspectives on environmental, economic, and social dimensions: An investigation of student views on sustainable development. Environmental Education Research, 22(8), 1115-1138.

Berglund, T., \& Gericke, N. (2018). Exploring the role of the economy in young adults' understanding of sustainable development. Sustainability, 10(8), 2738.

Berglund, T., Gericke, N., \& Chang Rundgren, S.-N. (2014). The implementation of education for sustainable development in Sweden: Investigating the sustainability consciousness among upper secondary students. Research in Science \& Technological Education, 32(3), 318-339.

Boeve-de Pauw, J., Donche, V., \& Van Petegem, P. (2011). Adolescents' environmental worldview and personality: An explorative study. Journal of Environmental Psychology, 31(2), 109-117.

Boeve-de Pauw, J., Gericke, N., Olsson, D., \& Berglund, T. (2015). The effectiveness of education for sustainable development. Sustainability, 7(11), 15693-15717.

Boeve-de Pauw, J., Jacobs, K., \& Van Petegem, P. (2014). Gender differences in environmental values: An issue of measurement? Environment and Behavior, 46(3), 373-397.

Boeve-de Pauw, J., \& Van Petegem, P. (2011a). A cross-cultural study of environmental values and their effect on the environmental behavior of children. Environment and Behavior, 45(5), 551-583.

Boeve-de-Pauw, J., \& Van Petegem, P. (2011b). The effect of Flemish eco-schools on student environmental knowledge, attitudes and affect. International Journal of Science Education, 33(11), 1513-1538.

Booth, C. (2009). A motivational turn for environmental ethics. Ethics \& the Environment, 14(1), 53-78.

Borg, C., Gericke, N., Höglund, H.-O., \& Bergman, E. (2012). The barriers encountered by teachers implementing education for sustainable development: Discipline bound differences and teaching traditions. Research in Science and Technological Education, 30(2), 185-207.

Borg, C., Gericke, N., Höglund, H.-O., \& Bergman, E. (2014). Subject- and experience-bound differences in teachers' conceptual understanding of sustainable development. Environmental Education Research, 20(4), 526-551.

Breiting, S., \& Wickenberg, P. (2010). The progressive development of environmental education in Sweden and Denmark. Environmental Education Research, 16(1), 9-37.

Bruun, O., \& Kalland, A. (2013). Images of nature: An introduction to the study of man-environment relations in Asia. In O. Bruun \& A. Kalland (Eds.), Asian perceptions of nature: A critical approach (pp. 1-24). New York: Routledge.

Cars, M., \& West, E. E. (2015). Education for sustainable society: Attainments and good practices in Sweden during the United Nations Decade for education for sustainable development. Environment, Development and Sustainability, 17(1), 1-21.

Chow, G., \& Lin, A.-I. (2002). Accounting for economic growth in Taiwan and mainland China: A comparative analysis. Journal of Comparative Economics, 30(3), 507-530.

Cohen, J. (1992). A power primer. Psychological Bulletin, 112(1), 155-159. 
Commonwealth Secretariat. (2007). Culture as the fourth pillar of sustainable development. In Small states: Economic review and basic statistics, vol. 11. Commonwealth Secretariat, London. https://doi. org/10.14217/smalst-2007-3-en. Accessed 26 Feb 2017.

Dunlap, R. E., Van Liere, K. D., Mertig, A. G., \& Jones, R. E. (2000). New trends in measuring environmental attitudes: Measuring endorsement of the New Ecological Paradigm: A revised NEP scale. Journal of Social Issues, 56(3), 425-442.

Eagly, A. H., \& Chaiken, S. (1993). The psychology of attitudes. Orlando: Harcourt Brace Jovanovich College Publishers.

Ekins, P. (2000). Economic growth and environmental sustainability: The prospects for green growth. Abingdon: Routledge.

Fang, W.-T., Lien, C.-Y., Huang, Y.-W., Han, G., Shyu, G.-S., Chou, J.-U., et al. (2018). Environmental literacy on ecotourism: A study on student knowledge, attitude, and behavioral intentions in China and Taiwan. Sustainability, 10(6), 1886.

Feng, L. (2012). Teacher and student responses to interdisciplinary aspects of sustainability education: What do we really know? Environmental Education Research, 18(1), 31-43.

Field, A. (2013). Discovering statistics using IBM SPSS statistics (4th ed.). London: Sage.

Gericke, N., Boeve-de Pauw, J., Berglund, T., \& Olsson, D. (2019). The Sustainability Consciousness Questionnaire: The theoretical development and empirical validation of an evaluation instrument for stakeholders working with sustainable development. Sustainable Development, 27, 35-49.

Giddings, B., Hopwood, B., \& O'Brien, G. (2002). Environment, economy and society: Fitting them together into sustainable development. Sustainable Development, 10(4), 187-196.

Gifford, R. (2011). The dragons of inaction: Psychological barriers that limit climate change mitigation and adaptation. American Psychologist, 66(4), 290-302.

Hair, J. F., Black, W. C., Babin, B. J., \& Anderson, R. E. (2010). Multivariate data analysis (7th ed.). Upper Saddle River, NJ: Pearson Prentice Hall.

Hair, J. F., Black, W. C., Babin, B. J., Anderson, R. E., \& Tatham, R. L. (2006). Multivariate data analysis (6th ed.). Upper Saddle River, NJ: Pearson Prentice Hall.

Herremans, I. M., \& Reid, R. E. (2002). Developing awareness of the sustainability concept. The Journal of Environmental Education, 34(1), 16-20.

Hofstede, G., \& McCrae, R. R. (2004). Personality and culture revisited: Linking traits and dimensions of culture. Cross-Cultural Research, 38(1), 52-88.

Hopkins, C. (2012). Twenty years of education for sustainable development. Journal of Education for Sustainable Development, 6(1), 1-4.

Inglehart, R., \& Oyserman, D. (2004). Individualism, autonomy, self-expression: The human development syndrome. In H. Vinken, J. Soeters, \& P. Ester (Eds.), Comparing cultures: Dimensions of culture in a comparative perspective (pp. 74-96). Leiden: Brill.

Jabareen, Y. (2008). A new conceptual framework for sustainable development. Environment, Development and Sustainability, 10(2), 179-192.

Jickling, B., \& Wals, A. E. J. (2008). Globalization and environmental education: Looking beyond sustainable development. Journal of Curriculum Studies, 40(1), 1-21.

John, L. C. K., Mei, W. S., \& Guang, Y. (2013). EE policies in three Chinese communities: Challenges and prospects for future development. In R. B. Stevenson, M. Brody, J. Dillon, \& A. E. J. Wals (Eds.), International handbook of research on environmental education (pp. 178-188). New York: Routledge.

Kalsoom, Q., \& Khanam, A. (2017). Inquiry into sustainability issues by preservice teachers: A pedagogy to enhance sustainability consciousness. Journal of Cleaner Production, 164, 1301-1311.

Kalsoom, Q., Khanam, A., \& Quraishi, U. (2017). Sustainability consciousness of pre-service teachers in Pakistan. International Journal of Sustainability in Higher Education, 18(7), 1090-1107.

Keep Sweden Tidy. (2017). What we do. http://www.hsr.se/english/what-we-do\#education. Accessed 18 May 2017.

Kennedy, E. H., Beckley, T. M., McFarlane, B. L., \& Nadeau, S. (2009). Why we don't "Walk the talk: Understanding the environmental values/behaviour gap in Canada. Human Ecology Review, 16(2), 151-160.

Kollmuss, A., \& Agyeman, J. (2002). Mind the gap: Why do people act environmentally and what are the barriers to pro-environmental behavior? Environmental Education Research, 8(3), 239-260.

Kopnina, H., \& Meijers, F. (2013). Education for sustainable development (ESD): Exploring theoretical and practical challenges. International Journal of Sustainability in Higher Education, 15(2), 188-207.

Kramming, K. (2017). Miljökollaps eller hållbar framtid?: Hur gymnasieungdomar uttrycker sig om miljöfrågor. Doctoral thesis, Uppsala university. Uppsala: Department of Social and Economic Geography, Uppsala University.

Laurie, R., Nonoyama-Tarumi, Y., McKeown, R., \& Hopkins, C. (2016). Contributions of education for sustainable development (ESD) to quality education: A synthesis of research. Journal of Education for Sustainable Development, 10(2), 226-242. 
Le Grange, L. (2013). The politics of needs and sustainability education. In R. B. Stevenson, M. Brody, J. Dillon, \& A. E. J. Wals (Eds.), International handbook of research on environmental education (pp. 126-132). New York: Routledge.

Liang, S.-W., Fang, W.-T., Yeh, S.-C., Liu, S.-Y., Tsai, H.-M., Chou, J.-Y., et al. (2018). A nationwide survey evaluating the environmental literacy of undergraduate students in Taiwan. Sustainability, 10(6), 1730.

Lin, L.-H., \& Ho, Y.-L. (2009). Confucian dynamism, culture and ethical changes in Chinese societies: A comparative study of China, Taiwan, and Hong Kong. The International Journal of Human Resource Management, 20(11), 2402-2417.

Liu, S.-Y., Yeh, S.-C., Liang, S.-W., Fang, W.-T., \& Tsai, H.-M. (2015). A national investigation of teachers' environmental literacy as a reference for promoting environmental education in Taiwan. The Journal of Environmental Education, 46(2), 114-132.

Ljungberg, J., \& Nilsson, A. (2009). Human capital and economic growth: Sweden 1870-2000. Cliometrica, 3(1), 71-95.

Lundegård, I., \& Wickman, P.-O. (2009). Identity transformation in education for sustainable development: A question of location. Scandinavian Journal of Educational Research, 53(5), 461-479.

Maleki, A., \& de Jong, M. (2014). A proposal for clustering the dimensions of national culture. CrossCultural Research, 48(2), 107-143.

McKeown, R., \& Hopkins, C. (2003). EE p ESD: Defusing the worry. Environmental Education Research, 9(1), 117-128.

Meinhold, J. L., \& Malkus, A. J. (2005). Adolescent environmental behaviors: Can knowledge, attitudes, and self-efficacy make a difference? Environment and Behavior, 37(4), 511-532.

Michalos, A. C., Creech, H., Swayze, N., Kahlke, P. M., Buckler, C., \& Rempel, K. (2012). Measuring knowledge, attitudes and behaviours concerning sustainable development among tenth grade students in Manitoba. Social Indicators Research, 106(2), 213-238.

Milfont, T. L., \& Duckitt, J. (2004). The structure of environmental attitudes: A first and second-order confirmatory factor analysis. Journal of Environmental Psychology, 24(3), 289-303.

Ministry of Education. (2014). The curriculum framework of twelve years compulsory education of Taiwan (in Chinese). Taipei: Ministry of Education.

Mogensen, F., \& Schnack, K. (2010). The action competence approach and the 'new' discourses of education for sustainable development, competence and quality criteria. Environmental Education Research, 16(1), 59-74.

Munda, G. (1997). Environmental economics, ecological economics, and the concept of sustainable development. Environmental Values, 6(2), 213-233.

Murray, P. (2011). The sustainable self: A personal approach to sustainability education. London: Earthscan Ltd.

Ntanos, S., Kyriakopoulos, G. L., Arabatzis, G., Palios, V., \& Chalikias, M. (2018). Environmental behavior of secondary education students: A case study at central Greece. Sustainability, 10(5), 1663.

Öhman, J. (2008). Environmental ethics and democratic responsibility: A pluralistic approach to ESD. In J. Öhman (Ed.), Values and democracy in education for sustainable development: Contributions from Swedish research (pp. 17-32). Malmö: Liber.

Öhman, M., \& Öhman, J. (2012). Harmoni eller konflikt? En fallstudie av meningsinnehållet i utbildning för hållbar utveckling. Harmony or conflict? A case study of the conceptual meaning of education for sustainable development. Nordic Studies in Science Education, 8(1), 59-72.

Olsson, D. (2018). Investigating effects of education for sustainable development in Sweden and beyond. Doctoral thesis, Karlstad university. Karlstad: Karlstad University Press.

Olsson, D., \& Gericke, N. (2016). The adolescent dip in students' sustainability consciousness: Implications for education for sustainable development. Journal of Environmental Education, 47(1), 35-51.

Olsson, D., \& Gericke, N. (2017). The effect of gender on students' sustainability consciousness: A nationwide Swedish study. The Journal of Environmental Education, 48(5), 357-370.

Olsson, D., Gericke, N., Boeve-de Pauw, J., Berglund, T., \& Chang, T. (2019). Green schools in Taiwan: Effects on student sustainability consciousness. Global Environmental Change, 54, 184-194.

Olsson, D., Gericke, N., \& Chang Rundgren, S.-N. (2016). The effect of implementation of education for sustainable development in Swedish compulsory schools-assessing pupils' sustainability consciousness. Environmental Education Research, 22(2), 176-202.

Rauch, F. (2002). The potential of education for sustainable development for reform in schools. Environmental Education Research, 8(1), 43-51.

Sandell, K., \& Öhman, J. (2010). Educational potentials of encounters with nature: reflections from a Swedish outdoor perspective. Environmental Education Research, 16(1), 113-132. 
Schultz, P. W., Gouveia, V. V., Cameron, L. D., Tankha, G., Schmuck, P., \& Franek, M. (2005). Values and their relationship to environmental concern and conservation behavior. Journal of Cross-Cultural Psychology, 36(4), 457-475.

Schwartz, S. (1992). Universals in the content and structure of values: Theoretical advances and empirical tests in 20 countries. In M. P. Zanna (Ed.), Advances in experimental social psychology (Vol. 25, pp. 1-65). San Diego: Academic Press.

Schwartz, S. H. (2004). Mapping and interpreting cultural differences around the world. In H. Vinken, J. Soeters, \& P. Ester (Eds.), Comparing cultures: Dimensions of culture in a comparative perspective (pp. 43-73). Leiden: Brill.

Spence, J. T., \& Hahn, E. D. (1997). The attitudes toward women scale and attitude change in college students. Psychology of Women Quarterly, 21(1), 17-34.

Thaman, K. H. (2002). Shifting sights: The cultural challenge of sustainability. International Journal of Sustainability in Higher Education, 3(3), 233-242.

The Swedish National Agency for Education. (2011a). Curriculum for the compulsory school system, the pre-school class and the leisure-time centre 2011. Stockholm: Skolverket.

The Swedish National Agency for Education. (2011b). Curriculum for the upper secondary school. Stockholm: Skolverket.

The Swedish National Agency for Education. (2017). Hållbar utveckling. https://www.skolverket.se/skolu tveckling/miljo-och-halsa/hallbar-utveckling. Accessed 18 May 2017.

Triandis, H. C. (2004). Dimensions of culture beyond Hofstede. In H. Vinken, J. Soeters, \& P. Ester (Eds.), Comparing cultures: Dimensions of culture in a comparative perspective (pp. 28-42). Leiden: Brill.

Tsai, W.-T. (2012). An investigation of Taiwan's education regulations and policies for pursuing environmental sustainability. International Journal of Educational Development, 32(2), 359-365.

UN. (2017). Sustainable development goals—17 goals to transform our World. http://www.un.org/sustainabl edevelopment/sustainable-development-goals/. Accessed 29 Jan 2018.

UN-DESA. (1992). Agenda21. https://sustainabledevelopment.un.org/outcomedocuments/agenda21. Accessed 11 April 2017.

UNESCO. (2006). Framework for the UNDESD international implementation scheme. Paris: UNESCO.

UNESCO. (2009). United nations decade of education for sustainable development (DESD, 2005-2014): Review of contexts and structures for education for sustainable development. Paris: UNESCO.

UNESCO. (2014). Roadmap for implementing the global action programme on education for sustainable development. Paris: UNESCO.

Vare, P., \& Scott, W. (2007). Learning for a change: Exploring the relationship between education and sustainable development. Journal of Education for Sustainable Development, 1(2), 191-198.

Wang, Y. (2016). Promoting sustainable consumption behaviors: The impacts of environmental attitudes and governance in a cross-national context. Environment and Behavior, 49(10), 1128-1155.

Wang, G., \& Huang, Y.-H. C. (2016). Contextuality, commensurability, and comparability in comparative research: Learning From Chinese relationship research. Cross-Cultural Research, 50(2), 154-177.

WENR. (2016). Education in Taiwan. http://wenr.wes.org/2016/06/education-in-taiwan. Accessed 23 Feb 2017.

Xiaoge, X. (1998). Asian values revisited. Media Asia, 25(1), 37-41.

Young, C.-Y., Ni, S.-P., \& Fan, K.-S. (2010). Working towards a zero waste environment in Taiwan. Waste Management and Research, 28(3), 236-244.

Yu, F.-L. T., Yuen, T. W.-K., \& Tang, E. C. H. (2019). Sustainable development and green education in mainland China, Taiwan and Hong Kong. International Journal of Pluralism and Economics Education, 10(1), 69-90.

Yueh, M.-C. M., \& Barker, M. (2011). Framework thinking, subject thinking and Taiwan-ness in environmental education. Australian Journal of Environmental Education, 27(1), 134-148.

Zhang, Y. B., Lin, M.-C., Nonaka, A., \& Beom, K. (2005). Harmony, hierarchy and conservatism: A cross-cultural comparison of confucian values in China, Korea, Japan, and Taiwan. Communication Research Reports, 22(2), 107-115.

Publisher's Note Springer Nature remains neutral with regard to jurisdictional claims in published maps and institutional affiliations. 